\title{
Germanica
}

\section{Nadja Lux, «Alptraum: Deutschland», Traumversionen und Traumvisionen vom «Dritten Reich»}

Freiburg i. Breisgau, Rombach, 2008, 444 pages

\section{Anne-Marie Corbin}

\section{OpenEdition}

\section{Journals}

Édition électronique

URL : http://journals.openedition.org/germanica/628

DOI : 10.4000/germanica.628

ISSN : 2107-0784

Éditeur

Université de Lille

\section{Édition imprimée}

Date de publication : 1 juin 2009

Pagination : 179-181

ISBN : 978-2-913857-23-0

ISSN : 0984-2632

Référence électronique

Anne-Marie Corbin, «Nadja Lux, «Alptraum: Deutschland», Traumversionen und Traumvisionen vom «Dritten Reich» », Germanica [En ligne], 44 | 2009, mis en ligne le 07 janvier 2010, consulté le 10 décembre 2020. URL : http://journals.openedition.org/germanica/628 ; DOI : https://doi.org/10.4000/ germanica.628

Ce document a été généré automatiquement le 10 décembre 2020.

(c) Tous droits réservés 


\title{
Nadja Lux, «Alptraum: Deutschland», Traumversionen und Traumvisionen vom «Dritten Reich»
}

Freiburg i. Breisgau, Rombach, 2008, 444 pages

\author{
Anne-Marie Corbin
}

\section{RÉFÉRENCE}

Nadja Lux, «Alptraum: Deutschland», Traumversionen und Traumvisionen vom «Dritten Reich» , Freiburg i. Breisgau, Rombach, 2008, 444 pages.

1 Il est des ouvrages que l'on a immédiatement envie de lire pour leur titre très évocateur. C'est le cas de la thèse de doctorat que publie Nadja Lux sur l'Allemagne, un cauchemar à l'époque du III Reich.

2 À cette époque - et ce dès 1933 - seule la sphère du rêve semble pouvoir échapper aux nazis et à leurs sbires. De nombreux textes en témoignent et ils vont constituer le domaine d'investigation de Nadja Lux. Parfois, ils sont réunis sous forme d'anthologie, comme celle de Charlotte Beradt, qui évoque l'omniprésence de la menace nazie, les mécanismes de mise au pas des individus et les compensations qu'ils trouvent dans leurs rêves pour échapper aux dangers qui les guettent dans la réalité. Beradt rassembla ces témoignages avant de quitter l'Allemagne nazie en 1939 avec son mari, un avocat et écrivain juif, et de se réfugier à Londres, puis aux États-Unis. Elle considérait que ce type de rêves ne pouvaient être décryptés à l'aide de la méthode freudienne, mais qu'ils relevaient plutôt du domaine politique. Nadja Lux va plus ou moins reprendre à son compte ces prémisses méthodologiques, tout comme le lien établi dès 1943 par Beradt avec les théories de Hannah Arendt sur le totalitarisme. Puis elle va s'attacher à les développer. Cependant, Nadja Lux ne suit pas C. G. Jung sur la trace des "archétypes", ces états affectifs et mythiques refoulés, imperceptibles pour les individus, mais qui existent sur le plan collectif. Elle définit, au contraire, le plan 
collectif comme étant constitué par le monde réel commun qui s'impose à tout individu (p. 37).

3 La première partie de son ouvrage est consacrée à la place du rêve dans l'histoire littéraire et culturelle occidentale. Des théories présentées, elle retient en particulier celle d'E. Lenk, publiée en 1983, Die unbewusste Gesellschaft, et y ajoute les travaux de Barbara Frischmuth et Richard Berger sur les liens entre la littérature et le rêve. Nadja Lux considère, en effet, que les théories psychanalytiques ou de psychologie littéraire ne parviennent pas à interpréter les rêves, car elles sont pré-littéraires. Elle insiste beaucoup sur le potentiel de subversion des rêves et sur la spécificité des rêves pendant la dictature nazie : soit des manifestes qui annoncent des lendemains meilleurs (Denis de Rougemont), soit le moyen de remplacer un dialogue devenu impossible (Theodor Haecker).

4 Le corpus comprend l'anthologie de Beradt. Il s'y ajoute des journaux intimes d'émigrés, mais aussi ceux de représentants de l'émigration intérieure, plus difficiles à cerner. Nadja Lux laisse de côté les rêves sans lien avec le présent historique de l'époque nazie et ceux qui traitent exclusivement de la violence physique ou de la vie dans les camps.

5 Dans la seconde partie de l'ouvrage, elle procède à une classification des nombreux écrits autobiographiques qu'elle commente. Il existe des rêves réalistes, comme ceux de Klaus Mann dans son journal intime, des cauchemars qui entraînent une réaction violente de révolte et de colère et qui engagent à l'action. Parfois, le rêveur est incapable de se mouvoir, paralysé, comme anesthésié. Le rêve est aussi un signal qui peut appeler à la vigilance ou mettre en garde lorsqu'il évoque par exemple le pouvoir de séduction de la propagande. La deuxième catégorie répertoriée par Lux est le rêve grotesque, semblable à une caricature, une manière de remettre en cause le régime, de renverser l'ordre établi qui s'apparente à l'expressionnisme et sa réaction contre l'expérience angoissante de la grande ville. Une dernière catégorie regroupe les rêves fantastiques, proches des contes et des mythes, un moyen de fuir la réalité, de rechercher des espaces où se réfugier : Nadja Lux y classe les écrits de Hans Carossa et Rudolf Leonhard. Elle conclut à une adéquation entre l'attitude éveillée et les différentes formes que prennent les rêves, les auteurs de l'émigration intérieure soulignant l'aspect fantastique de la réalité, un reflet du processus de déréalité qui se met en place chez eux.

6 Dans la troisième partie, Nadja Lux étudie le journal intime de Pierre de Lescure (une manière d'habiller les souvenirs sous une forme moins dangereuse, de les camoufler par mesure de sécurité face à l'occupant allemand) et Le Songe de Vercors, un écrit fictionnel qui permet à son auteur de réaliser une approche poétique du rêve tout en démasquant la réalité. Tous deux sont entrés dans la résistance et cherchent une réponse différente à l'horreur qu'il leur faut affronter au quotidien. Le rêve leur donne la possibilité d'être plus forts. Une dernière analyse est consacrée à divers écrits de Paula Ludwig, parus après guerre, et qui montrent bien que la mémoire publique peut être souvent remplacée par les documents de souvenirs privés.

7 Certes, les études de Nadja Lux sont fort intéressantes, mais l'on se demande souvent comment s'établit le corpus et s'il n'est pas dû au hasard des lectures. La conclusion de l'ouvrage est décevante dans la mesure où elle insiste sur l'omniprésence de la terreur dans la vie quotidienne à l'époque du III ${ }^{\mathrm{e}}$ Reich et sur le fait que le rêve est l'instrument d'une approche de la réalité non rationnelle. Il faudrait aller plus loin et vraiment 
montrer en quoi «nous sommes dans nos rêves moins raisonnables et convenables, mais aussi plus intelligents et capables de jugements qu'à l'état éveillé » (E. Fromm). 